\title{
MICOPLASMOSE RESPIRATÓRIA MURINA EM RATOS (RATTUS NORVEGICUS): revisão de literatura
}

\author{
Murine respiratory mycoplasmosis in rats (Rattus \\ norvegicus): literature review
}

\author{
Thais Urbano Palladino ${ }^{1}$; Patrícia Biegelmeyer ${ }^{2}$ (D) \\ *Autor Correspondente: Thais Urbano Palladino. Avenida Dois Córregos, 2696, \\ bloco 5, apto. 52, Jardim Nova Iguaçu, Piracicaba - SP. CEP: 13420-835. \\ E-mail: thaispalladino@gmail.com
}

\begin{abstract}
Como citar: PALLADINO, Thais Urbano; BIEGELMEYER, Patrícia. Micoplasmose respiratória murina em ratos (Rattus norvegicus): revisão de literatura. Revista de Educação Continuada em Medicina Veterinária e Zootecnia do CRMV-SP, São Paulo, v.19, n.1, 2021, e38100. Doi 10.36440/recmvz.v19i1.38100

Cite as: PALLADINO, Thais Urbano; BIEGELMEYER, Patrícia. Murine respiratory mycoplasmosis in rats (Rattus norvegicus): literature review. Journal of Continuing Education in Veterinary Medicine and Animal Science of CRMV-SP, São Paulo, v.19, n.1, 2021, e38100. Doi 10.36440/recmvz.v19i1.38100
\end{abstract}

\section{Resumo}

O Mycoplasma pulmonis é o agente etiológico primário da micoplasmose respiratória murina (MRM), importante patologia que acomete os ratos de laboratório, animais há muito utilizados para a realização de pesquisas experimentais e que, nos últimos anos, também passaram a ser criados como animais de companhia, com crescente presença em clínicas veterinárias. A MRM, uma patologia crônica que pode se apresentar de maneira subclínica, tem a sua instalação e progressão usualmente associadas a falhas de manejo. 0 conhecimento sobre a MRM em ratos, é fundamental para a convivência saudável dos tutores com esses animais, além de ser essencial para que os animais empregados em investigações científicas possibilitem a obtenção de resultados experimentais fidedignos.

Palavras-chave: Mycoplasma pulmonis. Ratos de companhia. Ratos de laboratório. Biotério.

\section{Abstract}

Mycoplasma pulmonis is the primary etiologic agent of murine respiratory mycoplasmosis (MRM), an important pathology of laboratory rats. For a long time, rats have been used in experimental research but nowadays it was observed an increasing number of rats treated as pets with a progressive presence of them in veterinary clinics. MRM is a chronic pathology often subclinical that is usually associated with inadequate management conditions. The objective of the present paper is to emphasize the importance of MRM in rats, to make possible a healthy coexistence of these animals with their owners and also for the achievement of reliable experimental results when they were applied in scientific investigations.

Keywords: Mycoplasma pulmonis. Pet rats. Laboratory rats. Bioterium. Animal house.

1 Discente em Medicina Veterinária, Universidade Metodista de Piracicaba (Unimep), Piracicaba, SP, Brasil

2 Docente do curso de Medicina Veterinária, Universidade Metodista de Piracicaba (Unimep), Piracicaba, SP, Brasil 


\section{Introdução}

As infecções respiratórias que acometem os ratos (Rattus norvegicus) são muito importantes e dentre elas a micoplasmose respiratória murina (MRM) é a mais frequente (BROWN; DONNELLY, 2012; TEIXEIRA, 2014; DUTTON, 2020). O seu agente etiológico primário é o Mycoplasma pulmonis, que coloniza, principalmente, o trato respiratório dos animais (BOECK et al., 2010; TEDESCO et al., 2011; BROWN; DONNELLY, 2012). Os ratos infectados podem passar toda a vida sem apresentar sinais clínicos, mas diversos fatores predisponentes podem amplificar o nível de patogenicidade da infecção (GRAHAM; SCHOEB, 2011; HANSEN; NIELSEN, 2015; ROMAGNANO, 2017).

$\mathrm{Na}$ atualidade há uma grande quantidade de informações sobre a biologia, anatomia, comportamento e fisiologia dos ratos, devido ao seu emprego em pesquisas científicas, pois foi o primeiro mamífero a ser empregado para este fim, e o terceiro a ter o seu genoma mapeado (GIBBS et al., 2004). Dentre as características que tornaram o $R$. norvegicus o animal mais utilizado como modelo experimental cumpre ser destacado: curto período de gestação e de ciclo estral, facilidade de manejo, fisiologia similar à humana e, particularmente, a presença de uma quantidade significativa de genes ortólogos aos genes humanos associados a doenças (GIBBS et al., 2004; GRANZOTTO et al., 2019; RÊGO et al., 2019). Devido à sua docilidade, inteligência e bom tamanho, os ratos passaram a ser ótimos animais de companhia, pois aprendem truques, se afeiçoam aos humanos com quem têm contato frequente e apresentam uma grande variedade de cores e padrões (LENNOX; BAUCK, 2012; TEIXEIRA, 2014; SAUNDERS, 2021).

O presente trabalho faz uma atualização de aspectos relevantes da micoplasmose respiratória murina em ratos (Rattus norvegicus).

\section{A micoplasmose respiratória murina}

O M. pulmonis tem grande importância na patogenicidade da MRM, mas a sua infecção isolada pode determinar sinais clínicos leves, ou até ausência de qualquer sinal (BOECK et al., 2010; GRAHAM; SCHOEB, 2011).

Em biotérios convencionais a infecção por M. pulmonis foi confirmada em cerca de $70 \%$ dos ratos, e mesmo em biotérios com barreiras sanitárias mais rígidas pode-se observar resultados próximos a 3\% de animais infectados (FERREIRA et al., 2008; TEDESCO et al., 2011; PIASECKI et al., 2017). A infecção por M. pulmonis em ratos de laboratório é apontada como uma importante causa de interferência em resultados experimentais, principalmente por sua característica subclínica (BOECK et al., 2010; TEDESCO et al., 2011; SOUZA et al., 2016). Em ratos de companhia, acreditase que a infecção por M. pulmonis esteja presente em 100\% dos animais (GRAHAM; SCHOEB, 2011; SAUNDERS, 2021).

\section{Progressão da micoplasmose respiratórỉa murina}

Os principais fatores responsáveis pelo desencadeamento dos sinais clínicos e progressão da MRM incluem características do hospedeiro e do agente, infecções concomitantes, condições ambientais do alojamento e manejo inadequado (GRAHAM; SCHOEB, 2011; TEIXEIRA, 2014; HANSEN; NIELSEN, 2015; SAUNDERS, 2021). O sistema imune do hospedeiro pode estar comprometido pela infecção primária do M. pulmonis e favorecer a instalação de infecções secundárias, com especial destaque para infecções pelos vírus Sendai e o da sialodacriloadenite (SDAV), bem como pela bactéria Filobacterium rodentium (BOECK et al., 2010; GRAHAM; SCHOEB, 2011; BROWN; DONNELLY, 2012; HERBERT et al., 2018; SAUNDERS, 2021). 
A permanência em ambiente com altos níveis de amônia é apontada como uma das principais condições predisponentes para a proliferação do M. pulmonis, a qual é atribuída à má ventilação, higienização e/ou uso de substratos inadequados (BOECK et al., 2010; LENNOX; BAUCK, 2012; TEIXEIRA, 2014; FROHLICH, 2020; SAUNDERS, 2021).

Animais submetidos a agentes estressores repetitivos ou crônicos podem apresentar desequilíbrio orgânico e se tornar mais suscetíveis a infecções por microrganismos (PAGLIARONE; SFORCIN, 2009; BROWN; DONNELLY, 2012). Dentre os principais agentes estressores para os animais pode ser destacada a exposição a temperaturas extremas, situações de medo (PAGLIARONE; SFORCIN, 2009), falta de higiene (LENNOX; BAUCK, 2012), ausência de locais em que possam se esconder da luz (ABOU-ISMAIL et al., 2010), ausência de enriquecimento ambiental e alimentar (LENNOX; BAUCK, 2012; RÊGO et al., 2019; FROHLICH, 2020; SAUNDERS, 2021), e também a privação da convivência com indivíduos da mesma espécie (RÊGO et al., 2019).

Algumas linhagens de ratos são mais resistentes ao M. pulmonis, e os animais jovens, geralmente são mais resistentes que os idosos (GRAHAM; SCHOEB, 2011; BROWN; DONNELLY, 2012).

Já foi observado que diferentes estirpes do M. pulmonis podem apresentar diferentes virulências (GRAHAM; SCHOEB, 2011; SHAW et al., 2013).

Deficiências de vitaminas $A$ e $E$ também foram descritas como agravantes na patogenicidade da MRM (GRAHAM; SCHOEB, 2011; BROWN; DONNELLY, 2012).

\section{O Mycoplasma pulmonis}

O M. pulmonis apresenta tropismo pelas células epiteliais do trato respiratório, ouvido médio e trato reprodutivo dos ratos e é pouco resistente em condições ambientais, sobretudo quando exposto à baixa umidade (GRAHAM; SCHOEB, 2011; TEIXEIRA, 2014; HANSEN; NIELSEN, 2015).

A transmissão vertical do M. pulmonis pode ocorrer quando o microrganismo atravessa a barreira placentária e atinge o líquido amniótico (GRAHAM; SCHOEB, 2011; BURTON et al., 2012). Contudo ele também pode se instalar no momento do nascimento ou durante a amamentação (BOECK et al., 2010; TEIXEIRA, 2014).

A transmissão horizontal do M. pulmonis é estabelecida por meio de aerossóis contaminados eliminados por espirros, bem como por contato direto ou sexual (BOECK et al., 2010; GRAHAM; SCHOEB, 2011; TEIXEIRA, 2014).

Alguns estudos sugerem a existência de potencial zoonótico para o M. pulmonis, sendo descritas infecções em pessoas que tiveram contato direto com os ratos, ou que manipularam fômites contaminados (FERREIRA et al., 2008; PIASECKI et al., 2017). Inquéritos sorológicos efetuados revelaram a ocorrência de positividade variando entre $15 \%$ e $76 \%$, em técnicos de laboratório, médicos-veterinários e tutores, contudo não houve a presença de sintomas respiratórios em nenhum dos casos (FERREIRA et al., 2008; PIASECKI et al., 2017).

\section{Sinais clínicos}

A MRM, doença de característica crônica, que se desenvolve de forma lenta e silenciosa, apresenta-se de maneira subclínica, principalmente em animais jovens (GRAHAM; SCHOEB, 2011; HERBERT et al., 2018; FROHLICH, 2020). Ratos com significativas lesões nos pulmões e diagnóstico positivo para MRM podem ser assintomáticos, e os sinais clínicos só aparecerão em estágios mais avançados ou ao final da doença (BOECK et al., 2010; BROWN; DONNELLY, 2012; CHAWLA et al., 2017). Destaca-se ainda que as manifestações clínicas são particularmente influenciadas por questões ambientais (BROWN; DONNELLY, 2012). 
Ratos saudáveis produzem porfirina em pequenas quantidades, porém a observação de tal substância em quantidade excessiva ao redor dos olhos e narinas é muito sugestiva da existência de infecção por M. pulmonis. Na MRM, a cromodacriorreia é observada em conjunto com outros sinais clínicos principais como espirros frequentes, dispneia e estertores (DUTTON, 2020). Outros sinais clínicos relatados são prurido cutâneo intenso, postura curvada, pelos arrepiados, acentuada perda de peso, apatia e a torção da cabeça (BROWN; DONNELLY, 2012; HANSEN; NIELSEN, 2015; ROMAGNANO, 2017; HERBERT et al., 2018; SAUNDERS, 2021).

Devido ao tropismo do M. pulmonis pelas células epiteliais do trato reprodutivo, tem sido constatado que até $40 \%$ das fêmeas acometidas pela MRM também apresentam infecção genital, acompanhada ou não de ooforite e salpingite (WEISBROTH; KOHN, 2019). 0 microrganismo também pode ser encontrado no trato reprodutivo de machos, contudo essa localização é mais frequente em fêmeas, resultando em infertilidade, mortes fetais e neonatais (BOECK et al., 2010; TEIXEIRA, 2014; HANSEN; NIELSEN, 2015; WEISBROTH; KOHN, 2019).

\section{Diagnóstico}

O diagnóstico da MRM é estabelecido pelo exame clínico do animal e confirmação laboratoria,l realizada com métodos que permitem a identificação do agente etiológico, como o PCR (Polymerase Chain Reaction), o ELISA (Enzyme Linked Immunonosorbent Assay) e a cultura (BOECK et al., 2010; MOTTA et al., 2012; SILVA et al., 2018; SAUNDERS, 2021). Em animais com sinais clínicos respiratórios, a utilidade destes métodos é limitada, pois a detecção do M. pulmonis ou de outro agente não é de grande importância para o direcionamento da escolha terapêutica. Nestes casos, opta-se pelo tratamento presuntivo de infecção por M. pulmonis (GRAHAM; SCHOEB, 2011; SAUNDERS, 2021).

A realização de testes preventivos em animais assintomáticos possibilita o estabelecimento de um diagnóstico precoce, importante para que a infecção não interfira em resultados experimentais, controla a sua disseminação e contribui para que o animal tenha um melhor prognóstico (BOECK et al., 2010; PIASECKI et al., 2017; SAUNDERS, 2021). Em animais sintomáticos, os exames complementares auxiliam a avaliação da evolução da MRM e são um recurso importante para o diagnóstico diferencial. Radiografias, em casos de maior progressão da MRM, podem revelar a presença de infiltrados linfoides e de abscessos pulmonares (GRAHAM; SCHOEB, 2011; SAUNDERS, 2021).

\section{Prevenção e tratamento}

As diferentes estirpes de M. pulmonis apresentam elevada capacidade de evasão do sistema imune do hospedeiro e, portanto, a prevenção será sempre mais eficaz que o tratamento (BROWN; DONNELLY, 2012; SHAW et al., 2013; SOUZA et al., 2016; YIWEN et al., 2021). A prevenção da MRM apoia-se fundamentalmente na adoção de procedimentos de manejo com destaque para: alojamento ventilado, com tamanho indicado e ambientado para a espécie, utilização de substratos adequados, fornecimento de alimentação de qualidade, manutenção da higiene e disponibilidade de variadas formas de enriquecimento ambiental (BROWN; DONNELLY, 2012; SAUNDERS, 2021). Finalizando, cumpre ser destacado que a aplicação correta dos conhecimentos da ciência de animais de laboratório é indispensável para a priorização do bem-estar dos animais utilizados em experimentação, adotando-se sempre o princípio dos 3Rs (redução, refinamento e substituição) em que as condições de alojamento e manejo estão incluídas no tópico do refinamento (ANTIORIO et al., 2019).

No tratamento para MRM são utilizados antibióticos para o controle da proliferação do microrganismo, além de outros medicamentos visando a diminuição dos sinais clínicos apresentados, com o objetivo de melhorar a qualidade de vida do animal, como, por exemplo, anti-inflamatórios e broncodilatadores (BROWN; DONNELLY, 2012; TEIXEIRA, 2014; SAUNDERS, 2021). A higiene do 
alojamento de animais submetidos a tratamento é um aspecto de grande importância (GRAHAM; SCHOEB, 2011; TEIXEIRA, 2014; SAUNDERS, 2021).

\section{Considerações finais}

A Micoplasmose respiratória murina é uma importante patologia detectada na maioria dos ratos de companhia e com alta prevalência em ratos de laboratório. 0 conhecimento das características do seu agente etiológico, dos aspectos biológicos dos ratos e do manejo adequado da espécie são aspectos primordiais para que se disponha de uma criação de animais saudáveis, que permitam a obtenção de resultados experimentais confiáveis. É de suma importância que os médicos-veterinários orientem tutores sobre os principais métodos preventivos da MRM em ratos de companhia, e que técnicos de laboratório e pesquisadores sejam capacitados para a adoção de procedimentos de manejo adequados para os animais utilizados em investigações científicas.

\section{Referências}

AABOU-ISMAIL, U. A. et al. The effects of enhancing cage complexity on the behavior and welfare of laboratory rats. Behavioural Processes, v. 85, n. 2, p. 172-180, out. 2010. DOl: https://doi. org/10.1016/j.beproc.2010.07.002.

ANTIORIO, A. T. F. B. et al. Capacitação em Ciência de Animais de Laboratório. Revista de Educação Continuada em Medicina Veterinária e Zootecnia do CRMV-SP, v. 17, n. 3, p 8-15, 2019. DOI: https:// doi.org/10.36440/recmvz.v17i3.37998. Disponível em: https://www.revistamvez-crmvsp.com.br/index. php/recmvz/article/view/37998. Acesso em: 2 nov. 2020.

BOECK, R. et al. Diagnóstico histopatológico molecular da infecção por Mycoplasma sp. em ratos mantidos em biotério convencional. Semina: Ciências Agrárias, Londrina, v. 31, n. 4, p. 1045-1050, out./dez. 2010. DOl: http://dx.doi.org/10.5433/1679-0359.2010v31n4p1045.

BROWN, C.; DONNELLY, T. M. Disease problems of small rodents. In: QUESENBERRY, K. E.; CARPENTER, J. W. (Org.). Ferrets, rabbits, and rodents: clinical medicine and surgery. 3. ed. Elsevier, 2011, p. 354-372.

BURTON, A. et al. Effect of experimental genital mycoplasmosis on gene expression in the fetal brain. Journal of Reproductive Immunology, v. 93, n. 1, p. 9-16, jan. 2012. DOI: https://doi.org/10.1016/j. jri.2011.11.005.

CHAWLA, S. et al. Clinical, pathological, and molecular investigation of Mycoplasma pulmonis-induced murina respiratory mycoplasmosis in a rat (Rattus norvegicus) colony. Veterinary World, v. 10, n. 11, p. 1378-1382, 2017. DOI: https://doi.org/10.14202/vetworld.2017.1378-1382. Disponível em: http:// www.veterinaryworld.org/Vol.10/November-2017/16.html. Acesso em: 16 mar. 2021.

DUTTON, M. Selected Veterinary Concerns of Geriatric Rats, Mice, Hamsters, and Gerbils. The Veterinary Clinics of North America Exotic Animal Practice, v. 23, n. 3, p. 525-548, sep. 2020. DOI: https://doi. org/10.1016/j.cvex.2020.04.001.

FERREIRA, J. B. et al. Detection of Mycoplasma pulmonis in laboratory rats and technicians. Zoonoses and Public Health, v.55, n. 5, p. 229-234,jun.2008.DOl:https://doi.org/10.1111/j.1863-2378.2008.01122.x. Disponível em: https://onlinelibrary.wiley.com/doi/abs/10.1111/j.1863-2378.2008.01122.x. Acesso em: 21 ago. 2020.

FROHLICH, J. Rats and Mice. In: QUESENBERRY, K. E. et al. (Org.). Ferrets, Rabbits, and Rodents: clinical medicine and surgery. 4. ed. Elsevier, 2020. p. 345-367. 
GIBBS, R. A. et al. Genome sequence of the Brown Norway rat yields insights into mammalian evolution. Nature, v. 428, p. 493-521, 2004. DOI: https://doi.org/10.1038/nature02426. Disponível em: https:// www.nature.com/articles/nature02426. Acesso em: 21 ago. 2020.

GRAHAM, J. E.; SCHOEB, T. R. Mycoplasma pulmonis in rats. Journal of Exotic Pet Medicine, v. 20, n. 4, p. 270-276, out. 2011. DOI: https://doi.org/10.1053/j.jepm.2011.07.004.

GRANZOTTO, N. et al. A importância histórica dos ratos no avanço da compreensão da biologia humana. In: RUIZ, V. R. R. (Org.). Comportamento Animal. Ponta Grossa, Paraná: Atena Editora, 2019. p. 1-17. DOI: https://doi.org/10.22533/at.ed.7351925011.

HANSEN, A. K.; NIELSEN, D. S. Handbook of Laboratory Animal Bacteriology. 2. ed. Boca Raton, Florida: CRC Press, 2015. p. 233-238.

HERBERT, R. A. et al. Lung, pleura, and mediastinum. In: SUTTIE, A. W. et al. (Org.). Boorman's pathology of the rat: Reference and atlas. 2. ed. USA:Academic Press, 2018. p. 437-466. DOl: https://doi.org/10.1016/ B978-0-12-391448-4.00023-X.

LENNOX, A. M.; BAUCK, L. Basic anatomy, physiology, husbandry, and clinical techniques. In: QUESENBERRY, K. E.; CARPENTER, J. W. (Org.). Ferrets, Rabbits, and Rodents: clinical medicine and surgery. 3. ed. Elsevier, 2012, p. 339-353. DOI: https://doi.org/10.1016/B978-1-4160-6621-7.00026-9.

MOTTA, M. C. et al. Detecção de Mycoplasma pulmonis no trato respiratório superior em roedores através da técnica de PCR. Revista da Sociedade Brasileira de Ciência em Animais de Laboratório, v. 1, n. 1, p. 87-91, jan./fev./mar. 2012.

PAGLIARONE, A. C.; SFORCIN, J. M. Estresse: revisão sobre seus efeitos no sistema imunológico. Biosaúde, Londrina, v. 11, n. 1, p. 57-90, jan./jun. 2009.

PIASECKI, T.; CHRZASTEK, K.; KASPRZYKOWSKA, U. Mycoplasma pulmonis of rodents as a possible human pathogen. Vector-borne and zoonotic diseases, v. 17, n. 7, p. 475-477, 2017. DOl: https://doi. org/10.1089/vbz.2016.2104.

RÊGO, J. F. et al. Ética e bem-estar em animais de laboratório. Revista da Sociedade Brasileira de Ciência em Animais de Laboratório, v.7, n. 1, p. 69-76, 2019.

ROMAGNANO, A. Mice, rats, gerbils, and hamsters. In: BALLARD, B.; CHEEK, R. (Org.). Exotic Animal Medicine for the Veterinary Technician. 3. ed. Ames, lowa: John Wiley \& Sons, Inc., 2017. p. 319-331.

SAUNDERS, R. Rats. In: KUBIAK, M. (Org.). Handbook of Exotic Pet Medicine. Hoboken, NJ: Wiley-Blackwell, 2020. p. 99-123. DOI: https://doi.org/10.1002/9781119389934.ch8.

SHAW, B. M. et al. EPS-I polysaccharide protects Mycoplasma pulmonis from phagocytosis. FEMS Microbiology Letters, v. 338, n. 2, p. 155-160, jan. 2013. DOl: https://doi.org/10.1111/1574$\underline{6968.12048 .}$.

SILVA, M. T. O. et al. Mixed antigen ELISA of Mycoplasma pulmonis and M. arthritidis for diagnosis of murine mycoplasmosis. Brazilian Journal of Veterinary Medicine, v. 40, n. 1, e96218, 2018. DOl: https:// doi.org/10.29374/2527-2179.bjvm096218. Disponível em: http://rbmv.org/index.php/BJVM/article/ view/962. Acesso em: 21 mar. 2021.

SOUZA, J. B. et al. Mycoplasma pulmonis, agente da micoplasmose respiratória murina: Revisão. Archives of Veterinary Science, v. 21, n. 4, p. 08-25, out. 2016. DOl: http://dx.doi.org/10.5380/avs.v21i4.39205. Disponível em: https://revistas.ufpr.br/veterinary/article/view/39205. Acesso em: 16 mar. 2021.

TEDESCO, J. T. G.; BLATT, S. L.; CORDOVA, C. M. M. Infecção por Mycoplasma pulmonis em ratos Wistar provenientes de biotério. Revista de Patologia Tropical, v. 40, n. 4, p. 279-286, out./dez. 2011. DOI: https://doi.org/10.5216/rpt.v40i4.16757. Disponivel em: https://www.revistas.ufg.br/iptsp/article/ view/16757. Acesso em: 21 ago. 2020. 
TEIXEIRA, V. N. Rodentia - Roedores exóticos (rato, camundongo, hamster, gerbilo, porquinho-da-índia e chinchila). In: CUBAS, Z. S.; SILVA, J. C.; CATÃO-DIAS, J. L. (Org.). Tratado de Animais Selvagens: Medicina Veterinária. 2. ed. São Paulo: Roca, 2014. p. 1169-1208.

WEISBROTH, S. H.; KOHN, D. F. Bacterial, Mycoplasmal, and Mycotic Infections. In: SUCKOW, M. A. et al. (Org.). The Laboratory Rat. 3. ed. Academic Press, 2019. p. 451-539.

YIWEN, C. et al. Infection Strategies of Mycoplasmas: unraveling the panoply of virulence factors. Virulence, v. 12, n. 1, p. 788-817, 2021. DOl: https://doi.org/10.1080/21505594.2021.1889813. 